\title{
Symptoms and impact of symptoms on function and health in patients with chronic obstructive pulmonary disease and chronic heart failure in primary health care
}

\author{
This article was published in the following Dove Press journal: \\ International Journal of COPD \\ 18 July 2014 \\ Number of times this article has been viewed
}

\section{Kersti Theander ${ }^{1,2}$ \\ Mikael Hasselgren ${ }^{2,3}$ \\ Kristina Luhr ${ }^{4}$ \\ Jeanette Eckerblad ${ }^{5}$ \\ Mitra Unosson ${ }^{5}$ \\ Ingela Karlsson'}

'Department of Nursing, Faculty of Health Science and Technology, Karlstad University, Karlstad, Sweden; 2Primary Care Research Unit, County Council of Värmland, Karlstad, Sweden; ${ }^{3}$ Department of Medicine, Örebro University, Örebro, Sweden; ${ }^{4}$ Family Medicine Research Centre, Örebro County Council, Örebro, Sweden; ${ }^{5}$ Department of Social and Welfare Studies, Faculty of Health Sciences, Linköping University, Linköping, Sweden
Correspondence: Kersti Theander Department of Nursing, Faculty of Health Science and Technology, Karlstad University, S-65I 88 Karlstad, Sweden $\mathrm{Tel}+46547001930$

Email kersti.theander@kau.se
Background: Patients with chronic obstructive pulmonary disease (COPD) and chronic heart failure (CHF) seem to have several symptoms in common that impact health. However, methodological differences make this difficult to compare.

Aim: Comparisons of symptoms, impact of symptoms on function and health between patients with COPD and CHF in primary health care (PHC).

Method: The study is cross sectional, including patients with COPD $(n=437)$ and CHF $(n=388)$, registered in the patient administrative systems of PHC. The patients received specific questionnaires - the Memorial Symptom Assessment Scale, the Medical Research Council dyspnea scale, and the Fatigue Impact Scale - by mail and additional questions about psychological and physical health.

Results: The mean age was $70 \pm 10$ years and $78 \pm 10$ years for patients with COPD and CHF respectively $(P=0.001)$. Patients with COPD $(n=273)$ experienced more symptoms $(11 \pm 7.5)$ than the CHF patients $(n=211)(10 \pm 7.6)$. The most prevalent symptoms for patients with COPD were dyspnea, cough, and lack of energy. For patients with CHF, the most prevalent symptoms were dyspnea, lack of energy, and difficulty sleeping. Experience of dyspnea, cough, dry mouth, feeling irritable, worrying, and problems with sexual interest or activity were more common in patients with COPD while the experience of swelling of arms or legs was more common among patients with CHF. When controlling for background characteristics, there were no differences regarding feeling irritable, worrying, and sexual problems. There were no differences in impact of symptoms or health.

Conclusion: Patients with COPD and CHF seem to experience similar symptoms. There were no differences in how the patients perceived their functioning according to their cardinal symptoms; dyspnea and fatigue, and health. An intervention for both groups of patients to optimize the management of symptoms and improve function is probably more relevant in PHC than focusing on separate diagnosis groups.

Keywords: chronic obstructive pulmonary disease, chronic heart failure, symptom, function, health

\section{Introduction}

Chronic obstructive pulmonary disease (COPD) and chronic heart failure (CHF) are predominant chronic diseases in older people that are expected to increase during the following years. ${ }^{1,2}$ In 2020, COPD is expected to be ranked as the third disease in terms of mortality, ${ }^{1}$ and patients with $\mathrm{CHF}$ will increase as the population ages. ${ }^{2}$ Patients with COPD or CHF are characterized by high comorbidity, multiple symptoms, and unmet 
needs. ${ }^{3-5}$ These patient groups are - to a large extent - managed in primary health care (PHC). ${ }^{6}$ Since these diagnoses are chronic, symptoms and function are central for the patients' health experiences. ${ }^{7,8}$ There is a need for new models of care that meet the specific needs of these populations in PHC.

Patients with COPD or CHF have - on average - nine symptoms or more ${ }^{9-11}$ that result from the primary disease, the treatment, comorbidity, or other causes. They have several symptoms in common, such as shortness of breath or dyspnea and lack of energy or fatigue. Many of the symptoms can cause significant distress ${ }^{9,11}$ that may impact on physical and emotional functioning. ${ }^{12}$

Shortness of breath is common and is prevalent in approximately $95 \%$ of patients with $\mathrm{COPD}^{9}$ and $56 \%$ among patients with $\mathrm{CHF} .{ }^{11}$ A large proportion of patients with COPD (62\%) report moderate or severe dyspnea in relation to walking distance or climbing. ${ }^{13}$ Another frequent and distressing symptom experienced by these patient groups is fatigue, ${ }^{14-16}$ which is estimated to occur in 43\%-58\% among patients with COPD, and in 50\% among patients with CHF. ${ }^{16}$ Fatigue limits physical and psychosocial functioning in patients with COPD,${ }^{17}$ while global and physical functioning are most affected in patients with $\mathrm{CHF} .{ }^{18}$ Anxiety and depressive symptoms are prevalent in both patient groups.

Among patients with COPD, depression varies between $8 \%-80 \%$ and among patients with CHF, 10\%-60\%. ${ }^{19}$ Furthermore, among patients with COPD, 50\% experience sleeping problems, ${ }^{20,21}$ which affect the patients' experience of other symptoms, as well as overall health. ${ }^{22,23}$ These studies suggest that patients with COPD and patients with $\mathrm{CHF}$ experience similar symptoms, both physical and psychological, and that the symptoms have an impact on functioning and health.

The great variation in prevalence between studies might be due to different designs and settings. Previous studies on symptoms are mainly performed on hospitalized patient populations suffering from severe COPD or $\mathrm{CHF},{ }^{9,10}$ younger patients, or patients from outpatient clinics..$^{9,10,24}$ Furthermore, the guidelines for COPD and CHF are mainly focused on the assessment and management of symptoms specific to the disease, ${ }^{25,26}$ leaving patients with a variety of potentially untreated symptoms. A recent study comparing patients with severe COPD and patients with $\mathrm{CHF}$ recruited from outpatient departments reported that only a minority of patients received symptom-related treatment. ${ }^{24}$ The lack of studies on patients with COPD or CHF managed in PHC limits direct comparisons and relevance for PHC. A better understanding of these patient groups in PHC is necessary, as it could be hypothesized that the patients experience similar symptoms and that the impact of symptoms - as a consequence - could be managed together. To our knowledge, there is no study reported that compares the symptoms and impact of symptoms on functioning between these patient groups in PHC.

The aim of this study was to compare the symptoms, the impact of symptoms on function, and health between patients with COPD and patients with CHF in PHC.

\section{Methods \\ Study design}

The study design was cross-sectional by using a postal questionnaire. The study was approved by the regional ethical review board in Uppsala, Sweden (EPN 2010/223).

\section{Sample}

Two patient groups, one with COPD and one with $\mathrm{CHF}$, were recruited from $\mathrm{PHC}$ in three counties located in central Sweden. The inclusion criteria were that patients should be registered in the PHC patient administrative systems with diagnosis COPD (International Statistical Classification of Diseases and Related Health Problems [ICD-10] J44) or CHF (ICD I50) during 2008-2009 and be 50 years of age or older. Patients registered with both COPD and CHF diagnoses were excluded.

In total, 8,923 patients with COPD and 9,263 patients with CHF diagnoses were identified in the patient administrative systems during that time period. The search in the patient administrative systems was performed by blinded administrative personnel in each county. As the number of inhabitants varied between the counties, random samples from each diagnosis group from each county were drawn in proportion to the number of inhabitants in each county. There were nearly 1 million inhabitants in the three counties altogether, and the distribution was $27 \%, 27 \%$, and $46 \%$, respectively of the inhabitants in each county. Therefore, of the 1,200 patients needed from each diagnosis group, approximately 325/325, 325/325, and 550/550 COPD/ CHF patients were randomly selected using the PASW Statistical 18 (SPSS Inc., Chicago, IL, USA) from the lists of patients from each county. In total, 1,218 patients with COPD and 1,215 patients with CHF were invited to participate in the study.

Of the selected patients with COPD, eleven had an unknown address, six died during the study period, and three claimed that they did not have COPD - leaving 1,198 qualified for the study. Of these, 437 (36\%) responded to the 
questionnaire. Of the selected patients with CHF, 20 had an unknown address, 18 died during the study period, and one had no heart failure, leaving 1,176 qualified for the study. Of these, 388 (33\%) answered the questionnaire.

\section{Measurements}

\section{Background characteristics}

Background characteristics consisted of eight items: age; sex; civil status (married/cohabiting or single); education (compulsory comprehensive school, upper secondary school, or university); employed (yes or no); smoker (current, former, or never smoked); years since diagnosis; and self-reported coexisting diseases (yes or no regarding myocardial infarction, atrial fibrillation, angina pectoris, asthma, kidney disease, liver disease, diabetes, cancer, COPD [only CHF group], CHF [only COPD group], or other).

\section{Symptoms}

The Memorial Symptom Assessment Scale (MSAS) ${ }^{27}$ measures prevalence (yes or no) of 32 common symptoms (26 physical and six psychological) within a time frame of "during the past week". MSAS is a valid and reliable instrument that has been used among both patients with $\mathrm{COPD}^{4}$ and patients with $\mathrm{CHF}^{11}$

Fatigue was measured by three questions concerning frequency, duration, and severity during the past month. ${ }^{28}$

The Hospital Anxiety and Depression Scale (HADS) ${ }^{29}$ assesses anxiety (seven items) and depression (seven items) using a 4-point Likert scale ranging from 0-3. Item scores are summarized, and each subscale score could range from 0-21, respectively. Values from $0-6$ indicate no anxiety/depression, 7-10 mild-to-moderate anxiety/depressed mood, and values $>10$ potential anxiety disorder/depression. HADS is proven to be valid and reliable and has been used among several different patient groups including patients with $\mathrm{COPD}^{30}$ and patients in PHC. ${ }^{31}$ Cronbach's alpha in the present study for the COPD group was 0.90 for the anxiety subscale and 0.85 for the depression subscale. The corresponding figures for the $\mathrm{CHF}$ group were 0.90 for the anxiety subscale and 0.84 for the depression subscale.

\section{Impact of symptoms on function}

The Medical Research Council dyspnea scale ${ }^{32}$ measures dyspnea in relation to five grades of physical activity that range from $0=$ "I only get breathless with strenuous exercise" to $4=$ "I get breathless when I wash myself or get dressed". The Medical Research Council dyspnea scale is frequently used and has shown validity when tested among COPD patients. ${ }^{33}$
The Fatigue Impact Scale (FIS) ${ }^{28}$ measures limitations due to fatigue in relation to cognitive (ten items), physical (ten items), and psychosocial (20 items) function during the past month. The FIS uses 5-point Likert scales ranging from $0=$ "no problem" to $4=$ "extreme problem". Item scores are summarized. The FIS total score could range from 0-160, the cognitive and physical subscales from $0-40$, and the psychosocial subscale from $0-80$. The FIS is tested for reliability and used among Swedish COPD patients. ${ }^{17}$ In the present study, Cronbach's alpha for the COPD group was 0.99 for the total scale, 0.97 for the cognitive, 0.96 for the physical, and 0.97 for the psychosocial subscales. For the CHF group, the parallel figures were 0.99 for the total scale, 0.96 for the cognitive, 0.96 for the physical, and 0.97 for the psychosocial subscales.

The Insomnia Severity Index (ISI) ${ }^{34}$ comprises seven items covering patients' perceptions concerning: the severity of sleeping problems (three items); satisfaction with sleeping pattern (one item); impact on daily living (one item); noticeability of sleeping problems (one item), and worry/distress related to sleeping problems (one item). Each item is rated on a 5 -point scale ranging from $0-4$, giving a summarized ISI score that could range from $0-28$. A score between $0-7$ indicates no clinically significant insomnia, 8-14 points to subthreshold insomnia, 15-21 shows moderate insomnia, and 22-28 indicates severe insomnia. ISI is shown to be a valid and reliable instrument. ${ }^{34}$ In the present study, Cronbach's alpha was 0.94 for the COPD group and 0.92 for the CHF group.

\section{Health}

Global health was measured by two questions. The patients rated their overall psychological and physical health from $1=$ "very poor" to 5= "very good". Single questions measuring perceptions of global health have showed validity and reliability. ${ }^{35}$

\section{Procedure}

The questionnaires, an information letter, and a return envelope were sent during November and December 2010. The questionnaires were filled out anonymously but with a code to have the possibility to send reminders. The code list was destroyed after the data collection. Two written reminders were sent 2 weeks apart to those who did not answer the first or second time.

\section{Statistical analysis}

Categorical data are expressed by frequencies and percentages, while continuous data are expressed by means and 
standard deviations (SD) and by median and quartile 1 to quartile 3 ( $q 1-q 3)$. The chi-square test was used to compare the COPD and CHF groups, and responders and nonresponders, when data were categorical (Fisher's exact test was used when $>25 \%$ of the cells had expected counts less than 5); otherwise, the student's $t$-test for independent groups was used.

To control for possible covariates, seven sequential logistic regression analyses were performed in regard to statistically significantly different symptom prevalence (no $=0$ versus yes $=1$ regarding shortness of breath, cough, dry mouth, problems with sexual interest or activity, swelling of arms or legs, feeling irritable, worrying) between the COPD group and the CHF group. In the first step, background characteristics which differed $(P<0.05)$ between the groups (age [from younger to older]; sex [men versus women]; civil status [married or cohabiting versus single]; employed [no versus yes]; current smoker [no versus yes]; former smoker [no versus yes]), together with number of self-reported coexisting diseases (from fewer to more), were included in the analyses. In the second step, the diagnosis group (COPD versus $\mathrm{CHF}$ ) was added.

Due to internal missing data, the numbers of subjects in different analyses varied, as indicated in text and tables. When $30 \%$ or more of answers on scales (HADS, FIS, and ISI) and subscales were missing, they were excluded. ${ }^{36}$ The $P$-values are two-sided and considered significant if $<0.05$. The Statistical Package for the Social Sciences software version 20 (SPSS; IBM Corporation, Armonk, NY, USA) was used.

\section{Results}

\section{Background characteristics}

The COPD group was younger, contained more women, and more patients were married or cohabiting compared to the CHF group. Furthermore, more of the COPD patients were working, and more of them were current or former smokers compared with patients in the CHF group. Many of the patients in both groups had coexisting diseases (selfreported), although there were fewer of them in the COPD group; $71 \%(n=311 / 437)$ compared with $88 \%$ in the $\mathrm{CHF}$ group ( $\mathrm{n}=342 / 388 ; P<0.001)$. The mean number of coexisting diseases among patients with COPD was 1.33 (SD 1.29) and among patients with CHF 1.71 (SD 1.21; $P<0.001)$. See Table 1.

Analyses comparing responders with nonresponders showed no differences among the patients with COPD regarding age and sex, although the responding patients
Table I Background characteristics in patients with COPD and patients with $\mathrm{CHF}$

\begin{tabular}{|c|c|c|c|}
\hline & $\begin{array}{l}\text { COPD } \\
n=437 \\
\text { Mean (SD) } \\
\text { Median } \\
(q I-q 3)\end{array}$ & $\begin{array}{l}\text { CHF } \\
\mathrm{n}=388\end{array}$ & $P$-value ${ }^{a}$ \\
\hline Age $(2 / 0)^{b}$ & $\begin{array}{l}70.44(9.75) \\
70(65-77)\end{array}$ & $\begin{array}{l}77.77(9.56) \\
79(72-85)\end{array}$ & $<0.001$ \\
\hline $\begin{array}{l}\text { Years since diagnosis } \\
(99 / 128)^{b}\end{array}$ & $\begin{array}{l}7.80(8.13) \\
5(3-10) \\
\text { n (\%) }\end{array}$ & $\begin{array}{l}8.24(8.5 I) \\
5(2-1 I) \\
\text { n (\%) }\end{array}$ & 0.518 \\
\hline $\begin{array}{l}\text { Sex } \\
\text { Men } \\
\text { Women }\end{array}$ & $\begin{array}{l}214(49) \\
223(51)\end{array}$ & $\begin{array}{l}221(57) \\
167(43)\end{array}$ & 0.022 \\
\hline $\begin{array}{l}\text { Civil status }(9 / 1)^{\mathrm{b}} \\
\text { Married/cohabiting } \\
\text { Single }\end{array}$ & $\begin{array}{l}270(63) \\
158(37)\end{array}$ & $\begin{array}{l}202(52) \\
185(48)\end{array}$ & 0.002 \\
\hline $\begin{array}{l}\text { Education }(14 / 12)^{b} \\
\text { Compulsory } \\
\text { comprehensive school }\end{array}$ & $221(52)$ & $212(56)$ & 0.410 \\
\hline $\begin{array}{l}\text { Upper secondary } \\
\text { school } \\
\text { University }\end{array}$ & $148(35)$ & $\begin{array}{l}125(33) \\
39(10)\end{array}$ & \\
\hline $\begin{array}{l}\text { Employed }(18 / 24)^{\mathrm{b}} \\
\text { Yes } \\
\text { No }\end{array}$ & $\begin{array}{l}58(14) \\
361(86)\end{array}$ & $\begin{array}{l}24(7) \\
340(93)\end{array}$ & 0.001 \\
\hline $\begin{array}{l}\text { Smoker }(5 / 13)^{\mathrm{b}} \\
\text { Current smoker } \\
\text { Former smoker } \\
\text { Never smoked }\end{array}$ & $\begin{array}{l}|3|(30) \\
267(62) \\
34(8)\end{array}$ & $\begin{array}{l}33(9) \\
139(37) \\
203(54)\end{array}$ & $<0.001$ \\
\hline $\begin{array}{l}\text { Self-reported } \\
\text { coexisting diseases }\end{array}$ & & & \\
\hline $\begin{array}{l}\text { Myocardial infarction } \\
\text { Atrial fibrillation }\end{array}$ & $\begin{array}{l}61(14) \\
60(14)\end{array}$ & $\begin{array}{l}85(22) \\
177(46)\end{array}$ & \\
\hline Angina pectoris & 64 (I5) & $99(26)$ & \\
\hline Asthma & 147 (34) & $40(10)$ & \\
\hline Kidney disease & $13(3)$ & $20(5)$ & \\
\hline Liver disease & $2(1)$ & $3(1)$ & \\
\hline Diabetes & $63(14)$ & $78(20)$ & \\
\hline Cancer & $32(7)$ & $39(10)$ & \\
\hline Other & $78(18)$ & $72(19)$ & \\
\hline COPD & & $47(12)$ & \\
\hline $\mathrm{CHF}$ & $61(14)$ & & \\
\hline
\end{tabular}

Notes: ${ }^{a}$ Comparison between the COPD and the CHF groups, chi-square test for categorical variables, and Student's $t$-test for continuous variables; 'number of patients with missing answers, the COPD and the CHF groups, respectively. Abbreviations: COPD, chronic obstructive pulmonary disease; $\mathrm{CHF}$, chronic heart failure; q, quartile.

with CHF were younger (mean 78.05 years [SD 9.35]) than the nonresponders (mean 81.28 years [SD 9.51]; $P<0.001$ ). Also, among the responding patients with $\mathrm{CHF}$, there were more men (57\%), compared with the nonresponders $(47 \%$; $P=0.001)$. Furthermore, the subgroup analysis of age groups among patients with $\mathrm{CHF}$ ( $<85$ years and $\geq 85$ years) was performed, due to the differences between the responders and the nonresponders. There was no age difference between 
the responders $(n=293)$ and the nonresponders $(n=477)$ in the CHF group $<85$ years (mean 74.34 years [SD 7.93] versus 75.06 years [SD 7.70]; $P=0.218)$. In the older subgroup $\geq 85$ years, the responders $(n=104)$ were younger than the nonresponders $(\mathrm{n}=363)$ (mean 88.51 years [SD 2.83] versus 89.46 years [SD 3.67]; $P=0.005$ ).

Comparisons of sex distribution in the same age subgroups showed that there were more men among the responding patients $(61 \%)$ than among the nonresponders $(54 \%$; $P=0.040)$ in the younger CHF group ( $<85$ years). In the older group ( $\geq 85$ years), there was no statistical difference regarding the proportion of men between the responders and the nonresponders ( $45 \%$ and $38 \%$, respectively; $P=0.205$ ).

\section{Symptoms}

According to the MSAS, the COPD group ( $\mathrm{n}=273 / 437$ ) experienced more symptoms (mean 11.30 [SD 7.48]) than the CHF group ( $\mathrm{n}=211 / 388$; mean 9.83 [SD 7.63]; $P=0.035$ ). Of the 32 symptoms, 16 symptoms were reported by $40 \%$ or more by both the COPD and CHF groups (Table 2). When controlling for background characteristics, the sequential logistic regression analyses (Table 3 ) showed that the patients with CHF were less likely to have the symptoms of shortness of breath, cough, and dry mouth, and more likely to have the symptoms of swelling of arms or legs, than patients with COPD.

There were no statistically significant differences between the groups regarding fatigue (Table 4). More than one-third of the patients - in both the COPD and the CHF groups experienced fatigue every day, approximately $10 \%$ of the patients experienced fatigue for more than 12 hours per day, and more than one-fifth experienced fatigue as one of their worst symptoms.

With respect to anxiety and depression (HADS), there were no statistically significant differences between the groups (Table 4). Also, $75 \%$ of the patients with COPD $(n=418)$ had no anxiety, 9\% reported mild to moderate anxiety, and $16 \%$ had potential anxiety disorders. In the CHF group, $75 \%(n=366)$ reported no anxiety, $11 \%$ mildto-moderate anxiety, and $14 \%$ had potential anxiety disorder $(P=0.359)$.

The corresponding percentages for depression were, for the patients with COPD ( $\mathrm{n}=419)$ : no depression $80 \%$; mild-to-moderate depressed mood $12 \%$; and $8 \%$ had potential depression. Among the patients with CHF ( $\mathrm{n}=367)$, $77 \%$ experienced no depression, $14 \%$ reported mild-tomoderate depressed mood and $9 \%$ had potential depression $(P=0.436)$.
Table 2 Prevalence of physical and psychological symptoms in patients with COPD and patients with CHF

\begin{tabular}{|c|c|c|c|}
\hline MSAS $^{a}$ & $\begin{array}{l}\text { COPD } \\
n=437 \\
n(\%)\end{array}$ & $\begin{array}{l}\begin{array}{l}\text { CHF } \\
n=388\end{array} \\
n(\%)\end{array}$ & $P$-value ${ }^{b}$ \\
\hline \multicolumn{4}{|l|}{ Physical symptoms } \\
\hline Shortness of breath $(37 / 50)^{c}$ & $331(83)$ & $249(74)$ & 0.003 \\
\hline Cough $(50 / 50)^{c}$ & $287(74)$ & $178(53)$ & $<0.001$ \\
\hline Lack of energy $(67 / 52)^{c}$ & $265(72)$ & $228(68)$ & 0.282 \\
\hline Dry mouth $(57 / 5 \mathrm{I})^{c}$ & $239(63)$ & I8I (54) & 0.015 \\
\hline $\begin{array}{l}\text { Numbness or tingling in } \\
\text { hands and feet }(61 / 50)^{c}\end{array}$ & $201(54)$ & $192(57)$ & 0.405 \\
\hline Pain $(64 / 63)^{c}$ & $194(52)$ & $|8|(56)$ & 0.327 \\
\hline Feeling drowsy $(8 \mathrm{I} / 79)^{\mathrm{c}}$ & $178(50)$ & $142(46)$ & 0.284 \\
\hline Dizziness $(61 / 57)^{c}$ & $173(46)$ & $155(47)$ & 0.951 \\
\hline \multicolumn{4}{|l|}{ interest or activity $(76 / 86)^{c}$} \\
\hline Feeling bloated $(80 / 66)^{c}$ & $143(40)$ & $112(35)$ & 0.120 \\
\hline Problems with urination $(64 / 55)^{c}$ & 145 (39) & I35 (4I) & 0.670 \\
\hline Itching $(69 / 61)^{c}$ & $122(33)$ & $118(36)$ & 0.510 \\
\hline Sweats $(65 / 60)^{c}$ & $119(32)$ & $97(30)$ & 0.439 \\
\hline Nausea $(70 / 65)^{c}$ & $102(28)$ & $84(26)$ & 0.533 \\
\hline Swelling of arms or legs $(57 / 45)^{c}$ & I0I (27) & I 46 (43) & $<0.001$ \\
\hline Lack of appetite $(72 / 60)^{c}$ & $93(26)$ & $86(26)$ & 0.834 \\
\hline Diarrhea $(72 / 63)^{c}$ & $88(24)$ & $83(26)$ & 0.745 \\
\hline Difficulty swallowing $(67 / 62)^{c}$ & $78(2 I)$ & $77(24)$ & 0.436 \\
\hline Constipation $(54 / 53)^{c}$ & $78(20)$ & $66(20)$ & 0.796 \\
\hline Change in skin $(6 I / 59)^{c}$ & $76(20)$ & $62(19)$ & 0.635 \\
\hline Hair loss $(57 / 56)^{c}$ & $60(16)$ & $50(15)$ & 0.748 \\
\hline Vomiting $(69 / 63)^{c}$ & $55(15)$ & $47(15)$ & 0.813 \\
\hline Weight loss $(58 / 50)^{c}$ & $51(14)$ & $53(16)$ & 0.320 \\
\hline Pain in mouth $(56 / 5 \mathrm{I})^{\mathrm{c}}$ & $46(12)$ & $36(11)$ & 0.583 \\
\hline Change in way food tastes $(65 / 54)^{c}$ & $42(11)$ & $37(11)$ & 0.942 \\
\hline “I don't look like myself" $(60 / 56)^{c}$ & $31(8)$ & $25(8)$ & 0.764 \\
\hline \multicolumn{4}{|l|}{ Psychological symptoms } \\
\hline Difficulty sleeping $(57 / 57)^{c}$ & $233(6 \mathrm{I})$ & $188(57)$ & 0.208 \\
\hline Feeling irritable $(62 / 58)^{c}$ & $208(56)$ & $|5|(46)$ & 0.010 \\
\hline Worrying $(68 / 66)^{c}$ & $200(54)$ & $150(47)$ & 0.047 \\
\hline Feeling nervous $(68 / 62)^{c}$ & $157(43)$ & $130(40)$ & 0.448 \\
\hline Feeling sad $(70 / 58)^{c}$ & $|5|(4 \mid)$ & $137(42)$ & 0.941 \\
\hline Difficulty concentrating $(68 / 65)^{c}$ & $149(40)$ & $|3|(4 \mid)$ & 0.932 \\
\hline
\end{tabular}

Notes: aSymptoms are sorted in descending order, according to prevalence in the COPD group; 'comparison between the COPD and the CHF groups, chi-square test, or Fisher's exact test; 'number of patients with missing answers, the COPD and the CHF groups, respectively.

Abbreviations: COPD, chronic obstructive pulmonary disease; $\mathrm{CHF}$, chronic heart failure; MSAS, Memorial Symptom Assessment Scale.

\section{Impact of symptoms on function}

There were no statistically significant mean differences between the COPD and the CHF groups in dyspnea in relation to physical activity, functional limitations due to fatigue, or insomnia (Table 5). In the COPD group ( $\mathrm{n}=412 / 437), 52 \%$ had no clinically significant insomnia, $27 \%$ were in the range of subthreshold insomnia, $16 \%$ had moderate insomnia, and $5 \%$ reported severe insomnia. The corresponding figures for 
Table 3 Sequential logistic regression analyses ${ }^{\mathrm{a}}$

\begin{tabular}{|c|c|c|c|c|c|c|c|}
\hline & $\begin{array}{l}\text { Shortness } \\
\text { of breath }\end{array}$ & Cough & $\begin{array}{l}\text { Dry } \\
\text { mouth }\end{array}$ & $\begin{array}{l}\text { Problems with } \\
\text { sexual interest } \\
\text { or activity } \\
\end{array}$ & $\begin{array}{l}\text { Swelling } \\
\text { of arms } \\
\text { or legs } \\
\end{array}$ & $\begin{array}{l}\text { Feeling } \\
\text { irritable }\end{array}$ & Worrying \\
\hline & OR & OR & OR & OR & OR & OR & OR \\
\hline & $95 \% \mathrm{Cl}$ & $95 \% \mathrm{Cl}$ & $95 \% \mathrm{Cl}$ & $95 \% \mathrm{Cl}$ & $95 \% \mathrm{Cl}$ & $95 \% \mathrm{Cl}$ & $95 \% \mathrm{Cl}$ \\
\hline & $P$-value & $P$-value & $P$-value & $P$-value & $P$-value & $P$-value & $P$-value \\
\hline \multicolumn{8}{|l|}{ Step $I^{b}$} \\
\hline \multirow[t]{3}{*}{ Age (years, older) } & 0.10 & 1.00 & 1.02 & 0.96 & 1.00 & 0.98 & 0.98 \\
\hline & $0.97-1.02$ & $0.98-1.03$ & $1.00-1.04$ & $0.94-0.98$ & $0.98-1.02$ & $0.96-1.00$ & $0.97-1.01$ \\
\hline & 0.733 & 0.702 & 0.037 & 0.001 & 0.995 & 0.094 & 0.129 \\
\hline \multirow[t]{3}{*}{ Sex (women) } & 1.18 & 1.49 & 2.16 & 0.33 & 1.38 & 1.33 & 1.91 \\
\hline & $0.79-1.77$ & $1.05-2.12$ & $1.54-3.03$ & $0.22-0.48$ & $0.97-1.95$ & $0.96-1.85$ & $1.37-2.66$ \\
\hline & 0.414 & 0.026 & $<0.00$ I & $<0.001$ & 0.072 & 0.091 & $<0.00$ I \\
\hline \multirow[t]{3}{*}{ Civil status (single) } & 1.16 & 0.79 & 1.27 & 0.63 & 1.51 & 0.75 & 1.21 \\
\hline & $0.76-1.76$ & $0.55-1.14$ & $0.89-1.81$ & $0.42-0.93$ & $1.05-2.16$ & $0.53-1.06$ & $0.85-1.70$ \\
\hline & 0.491 & 0.201 & 0.182 & 0.019 & 0.025 & 0.105 & 0.292 \\
\hline \multirow[t]{3}{*}{ Employed (yes) } & 0.65 & 0.51 & 0.71 & 0.96 & 0.83 & 0.95 & 0.93 \\
\hline & $0.35-1.25$ & $0.28-0.93$ & $0.40-1.27$ & $0.53-1.73$ & $0.44-1.57$ & $0.54-1.64$ & $0.53-1.63$ \\
\hline & 0.196 & 0.028 & 0.253 & 0.883 & 0.568 & 0.839 & 0.795 \\
\hline \multirow[t]{3}{*}{ Current smoker (yes) } & 0.94 & 2.31 & 0.90 & 1.11 & 0.63 & 1.10 & 1.15 \\
\hline & $0.48-1.86$ & I.23-4.32 & $0.50-1.62$ & $0.58-2.10$ & $0.34-1.17$ & $0.62-1.94$ & $0.65-2.05$ \\
\hline & 0.865 & 0.009 & 0.724 & 0.760 & 0.142 & 0.743 & 0.638 \\
\hline \multirow[t]{3}{*}{ Former smoker (yes) } & 1.02 & 0.96 & 1.00 & 1.27 & 0.87 & 1.50 & 0.84 \\
\hline & $0.6 \mathrm{I}-1.69$ & $0.61-1.50$ & $0.63-1.57$ & $0.76-2.10$ & $0.56-1.36$ & $0.97-2.32$ & $0.54-1.31$ \\
\hline & 0.952 & 0.858 & 0.993 & 0.359 & 0.535 & 0.069 & 0.446 \\
\hline Self-reported coexisting & 1.59 & 1.22 & 1.29 & 1.22 & 1.19 & 1.15 & 1.09 \\
\hline \multirow[t]{2}{*}{ diseases (\#, higher) } & $1.32-1.92$ & $1.06-1.40$ & $1.12-1.47$ & $1.06-1.40$ & $1.04-1.36$ & $1.01-1.30$ & $0.96-1.24$ \\
\hline & $<0.001$ & 0.005 & $<0.001$ & 0.004 & 0.009 & 0.031 & 0.178 \\
\hline \multicolumn{8}{|l|}{ Step $2^{c}$} \\
\hline \multirow[t]{3}{*}{ Diagnosis group (CHF) } & 0.43 & 0.39 & 0.48 & 0.68 & 1.67 & 0.82 & 0.79 \\
\hline & $0.27-0.69$ & $0.26-0.58$ & $0.33-0.71$ & $0.45-1.02$ & $1.13-2.46$ & $0.57-1.19$ & $0.54-1.15$ \\
\hline & $<0.001$ & $<0.001$ & $<0.00$ I & 0.064 & 0.010 & 0.301 & 0.221 \\
\hline
\end{tabular}

Notes: Control of background characteristics and diagnosis group on prevalence of shortness of breath, cough, dry mouth, problems with sexual interest or activity, swelling of arms or legs, feeling irritable, and worrying measured with MSAS. ${ }^{2} \mathrm{n}$ varies between 623-69I in the analyses. ${ }^{\circ}$ Step I age (from younger to older); sex (men/women); civil status (married or cohabiting/single); employed (no/yes); current smoker (no/yes); former smoker (no/yes); self-reported coexisting diseases (from fewer to more). 'Step 2 diagnosis group (COPD/CHF).

Abbreviations: $\mathrm{Cl}$, confidence interval; MSAS, Memorial Symptom Assessment Scale; CHF, chronic heart failure; COPD, chronic obstructive pulmonary disease.

the CHF group $(\mathrm{n}=358 / 388)$ were $51 \%, 30 \%, 17 \%$, and $3 \%$, respectively $(P=0.316)$.

\section{Health}

The mean scores for global psychological health were 3.59 (SD 1.07) for patients with COPD $(n=430 / 437)$ and 3.59 (SD 1.08) for those with CHF ( $\mathrm{n}=371 / 388 ; P=0.935$ ), while the mean scores for global physical health were 2.90 (SD 1.02) and 2.95 (SD 1.12), respectively $(P=0.542)$.

\section{Discussion}

The main results of this study suggest that patients with COPD or CHF in PHC experience many symptoms that are similar. Also, 16 symptoms out of the 32 MSAS symptoms were reported by $40 \%$ or more of the patients in both groups. Among the top five prevalent symptoms for both patient groups were shortness of breath, lack of energy, and difficulty sleeping. Differences among the top five prevalent symptoms were cough, dry mouth, numbness or tingling in hands and feet, and pain. Experiences of shortness of breath, cough, and dry mouth were more common in patients with COPD, while the experience of swelling of arms or legs was more common among patients with $\mathrm{CHF}$ when controlling for background characteristics. Both COPD and CHF patients had similar functional limitations due to dyspnea, fatigue, and sleeping problems.

Patients with COPD or CHF experience many symptoms. Many of the symptoms in this study have previously been reported, but in isolation ${ }^{34}$ and separately for patients with COPD or with CHF, making comparisons difficult. The symptom prevalence among the patient groups in this study is comparable with the findings in the studies by 
Table 4 Experience of fatigue, anxiety, and depression in patients with COPD and patients with $\mathrm{CHF}$

\begin{tabular}{|c|c|c|c|}
\hline & $\begin{array}{l}\text { COPD } \\
n=437 \\
\end{array}$ & $\begin{array}{l}\begin{array}{l}\text { CHF } \\
n=388\end{array} \\
\end{array}$ & $P$-value ${ }^{a}$ \\
\hline & n (\%) & n (\%) & \\
\hline $\begin{array}{l}\text { Fatigue frequency during } \\
\text { last month }(28 / 35)^{b}\end{array}$ & & & 0.125 \\
\hline Not a problem & $142(35)$ & $126(36)$ & \\
\hline I-7 days & $67(16)$ & $52(15)$ & \\
\hline 8-14 days & $29(7)$ & $15(4)$ & \\
\hline$|5-2|$ days & $18(4)$ & $10(3)$ & \\
\hline $22-30$ days & $14(3)$ & $6(2)$ & \\
\hline Every day & $139(34)$ & $143(4 \mid)$ & \\
\hline $\begin{array}{l}\text { Fatigue duration per } \\
\text { day }(38 / 47)^{b}\end{array}$ & & & 0.269 \\
\hline No experience & $124(31)$ & $101(30)$ & \\
\hline$<6$ hours & $164(4 \mid)$ & $123(36)$ & \\
\hline $6-12$ hours & $77(19)$ & $79(23)$ & \\
\hline I3-24 hours & $34(9)$ & $38(I I)$ & \\
\hline Fatigue severity $(43 / 52)^{b}$ & & & 0.608 \\
\hline Not a problem & $164(42)$ & I37 (4I) & \\
\hline $\begin{array}{l}\text { One of my least } \\
\text { severe symptoms }\end{array}$ & $148(38)$ & $119(35)$ & \\
\hline \multirow{3}{*}{$\begin{array}{l}\text { One of my } \\
\text { symptoms }\end{array}$} & $82(2 I)$ & $80(24)$ & \\
\hline & Mean (SD) & Mean (SD) & \\
\hline & Median (qI-q3) & Median (qI-q3) & \\
\hline \multirow[t]{2}{*}{ HADS anxiety $(19 / 22)^{\mathrm{b}}$} & $5.22(4.60)$ & $4.95(4.5 \mathrm{I})$ & 0.406 \\
\hline & $4(2-7)$ & $4(I-7)$ & \\
\hline HADS depression & $4.53(3.75)$ & $4.83(3.88)$ & 0.269 \\
\hline$(|8 / 2|)^{\mathrm{b}}$ & $4(2-7)$ & $4(2-7)$ & \\
\hline
\end{tabular}

Notes: aComparison between the COPD and the CHF groups, chi-square test for categorical variables and Student's t-test for continuous variables; 'bumber of patients with missing answers, the COPD and the CHF groups, respectively.

Abbreviations: COPD, chronic obstructive pulmonary disease; CHF, chronic heart failure; HADS, Hospital Anxiety and Depression Scale; SD, standard deviation; q, quartile.

Blinderman et al, 9,11 in which the symptoms were also assessed in patients with COPD or CHF using the MSAS questionnaire. As the patients experience a broad spectrum of symptoms, it is necessary to assess symptoms more broadly than only the disease-specific symptoms. Symptoms such as numbness or tingling in hands and feet, pain, feeling drowsy, dizziness, and difficulty sleeping are symptoms that need to be addressed. Otherwise, the patients may be left with an amount of symptoms that could accelerate and affect each other. ${ }^{37}$ However, a low concordance between patients and physicians when assessing symptoms has been found.$^{38}$ It is unclear if the large number of symptoms that patients experience are disclosed during a consultation. This indicates that the assessment of physical and psychological symptoms in these groups of patients should be more comprehensive and individualized.

In this study, the prevalence of shortness of breath, cough, and dry mouth is higher $(9 \%, 21 \%, 9 \%$, respectively) for patients with COPD. Although there are statistically
Table 5 Impact of dyspnea, fatigue, and sleep on functioning in patients with COPD and patients with $\mathrm{CHF}$

\begin{tabular}{|c|c|c|c|}
\hline & $\begin{array}{l}\text { COPD } \\
n=437 \\
\end{array}$ & $\begin{array}{l}\begin{array}{l}\text { CHF } \\
n=388\end{array} \\
\end{array}$ & $P$-value \\
\hline & $\begin{array}{l}\text { Mean (SD) } \\
\text { Median } \\
(q \mid-q 3)\end{array}$ & $\begin{array}{l}\text { Mean (SD) } \\
\text { Median } \\
(q I-q 3)\end{array}$ & \\
\hline MRC dyspnea & $2.1(1.3)$ & $2.0(1.4)$ & 0.720 \\
\hline scale $(16 / 26)^{b}$ & $2(I-3)$ & $2(I-3)$ & \\
\hline \multicolumn{4}{|l|}{$\mathrm{FIS}^{\mathrm{c}}$} \\
\hline \multirow[t]{2}{*}{ Cognitive $(23 / 32)^{b}$} & $10.4(10.1)$ & II.3 (9.8) & 0.322 \\
\hline & $8(2-16)$ & $9(2-18)$ & \\
\hline \multirow[t]{2}{*}{ Physical $(20 / 26)^{b}$} & $14.0(10.9)$ & I5.I (I0.9) & 0.226 \\
\hline & $12(5-22)$ & $14(6-25)$ & \\
\hline \multirow[t]{2}{*}{ Psychosocial (19/24) } & $21.6(19.6)$ & $23.4(19.3)$ & 0.307 \\
\hline & $16(5-35)$ & $22(5-37)$ & \\
\hline \multirow[t]{2}{*}{ Total $(24 / 37)^{\mathrm{b}}$} & $46.2(39.4)$ & $49.9(38.6)$ & 0.296 \\
\hline & $36(13-73)$ & $43(16-79)$ & \\
\hline \multirow[t]{2}{*}{ ISI $(25 / 30)^{\mathrm{b}}$} & $8.5(7.0)$ & $8.4(6.5)$ & 0.765 \\
\hline & $7(2-13)$ & $7(3-13)$ & \\
\hline
\end{tabular}

Notes: ${ }^{2}$ Comparison between the COPD and the CHF groups, Student's t-test; bnumber of patients with missing answers, the COPD and the CHF groups, respectively; ' patients who claimed no fatigue have not answered these questions. Abbreviations: COPD, chronic obstructive pulmonary disease; CHF, chronic heart failure; MRC, Medical Research Council dyspnea scale; FIS, Fatigue Impact Scale; ISI, Insomnia Severity Index; SD, standard deviation; q, quartile.

significant differences, the number of patients that experiences the symptoms is high also in the CHF group. Due to different etiology for patient with COPD or CHF, some symptom interventions need to be disease specific; on the other hand, interventions may be similar although different etiology. For instance, patients with COPD or CHF with shortness of breath need specific pharmacological treatment, while recommendations for both patient groups are physical activity. ${ }^{25,26}$ Dry mouth in patients with COPD could be related to anticholinergic treatment; whereas, in patients with CHF, it could be related to treatment with diuretics and restriction in fluid intake. Interventions for dry mouth are general, such as glycerol spray and chewing gum. ${ }^{39}$ As expected, the swelling of arms and feet was more prevalent in patients with CHF.

More than $40 \%$ of both patient groups experienced all of the measured psychological symptoms. Feeling irritable and worrying were not related to COPD or CHF when controlled for age, sex, and coexisting disease. Furthermore, there were no significant differences between the patient groups in relation to anxiety and depression. The psychological symptoms seem to be related to other aspects than diagnosis and are multifactorial, particularly in older people. The high prevalence of psychological symptoms must be assessed to avoid for example, social isolation, and nonadherence to medical treatment. ${ }^{40}$ Furthermore, both anxiety and depression are 
related to higher exacerbation risk, increased general and emergency care visits, rehospitalization, and higher medical costs in patients with COPD and $\mathrm{CHF}^{40}$ Current evidence suggests that pulmonary and cardiac rehabilitation may offer improvement in anxiety and depression. ${ }^{19}$

It is interesting that few patients with COPD and CHF reported nutritional and gastrointestinal specific symptoms. In the guidelines, ${ }^{25,26}$ nutritional interventions are based on malnutrition. For patients with COPD in PHC other interventions, such as balanced diet must be discussed; as pointed out by other researchers recently. ${ }^{41,42}$

Dyspnea, fatigue, and sleeping problems had similar impact on functioning in both patient groups. Furthermore, psychological and physical health was also similar. The results indicate that only disease-specific management could be a less promising strategy when caring for COPD and CHF patients in PHC. As the patient groups share similar symptoms, impact of symptoms and health and also as COPD and CHF are comorbidities it could be promising for the patients, health care system and costs to combine these groups in a management program. This needs to be further studied. There is evidence that rehabilitation improves the experiences of dyspnea and fatigue in hospital settings; ${ }^{43,44}$ in PHC settings, however, it is not proved. In PHC, it is not even common for patients to have access to rehabilitation, symptom management, or education. ${ }^{45}$ The goal with nonpharmacological management of COPD and CHF is to improve symptoms and functioning and to promote comprehensive education and counseling. ${ }^{26} \mathrm{~A}$ new paradigm of care that focuses on symptoms and their impact on function and health is needed in PHC. Recently, exercise rehabilitation intervention for both these groups together resulted in similar improvements in exercise performance and health; ${ }^{46}$ the rehabilitation consisted of supervised physical training and education. The study included patients from community CHF nurses' and physicians' referrals to pulmonary rehabilitation, making it difficult to make generalizations into PHC.

\section{Limitations}

This study has strengths and limitations. The patients were classified according to ICD-10. Classification according to ICD-10 is not well-established in PHC; for instance, a recent study ${ }^{47}$ has found that $60 \%-70 \%$ of patients with $\mathrm{CHF}$ or ischemic heart disease were registered. An interesting - and important - issue to investigate had been the experiences of patients suffering from both COPD and CHF. In this study, very few persons were found who were registered in the patient administrative systems with both diagnoses; therefore, they were excluded. However, the patients were asked in the questionnaire about several potential coexisting diseases, including COPD and CHF. The results according to patients' self-reported comorbidity suggest that there may be more COPD patients diagnosed with $\mathrm{CHF}$ and vice versa than found in the patient administrative systems. Future research should address the situation for patients who are diagnosed with both of these chronic conditions. Here, self-reported COPD and CHF were treated as other self-reported conditions. Furthermore, overall self-reported comorbidity was low in this study, with mean values of 1.3 (COPD) and 1.7 (CHF), as compared to other studies. ${ }^{46,47}$ In the case where the self-reported comorbidities were underreported by the patients, we have no reason to assume that the underreporting differed in the COPD or CHF groups. Although the number of coexisting diseases could have been underestimated, the symptom prevalence is high and comparable with other studies. ${ }^{9,11}$ Moreover, as expected, the number of comorbidities was a significant variable in all logistic analyses with one exception. The possibility to recruit patients without comorbidity is difficult and is not representative for patients in $\mathrm{PHC}$.

Despite two reminders, the response rates were low $36 \%$ and $33 \%$, respectively - in the two groups. The low response rate could be due to the fact that the patient groups are elderly (in particular, the patients with $\mathrm{CHF}$ ) and that an extensive questionnaire was used..$^{50}$ In future studies, questionnaires with a home interview could be considered in relation to costs and response rate. Cognitive impairment like dementia increases with age, and patients could be unable or unwilling to participate in studies. ${ }^{50}$ In the present study, it was not feasible to list cognitive impairment as an exclusion criterion. Also, patients who were seriously ill with many symptoms could have had difficulty completing the questionnaire. The comparisons between the respondents and nonrespondents for the COPD group showed no differences regarding age and sex while the respondents in the CHF group were younger patients and more men. However, age subgroup analysis showed no differences among patients younger than 85 years. This indicates a participant selection bias in that the oldest patients and women with CHF are not fully represented in the study, which should be kept in mind when interpreting the results. Difficulty in recruiting older patients or a disproportionate number of women with $\mathrm{CHF}$ has also been found in other studies, ${ }^{11,24}$ which may limit the generalization of the results. The other studies ${ }^{11,24}$ indicate that the results are not overestimated. COPD patients are 
normally approximately 10 years younger than CHF patients. The difference in age is most likely the reason for the difference in civil and working status among the groups.

With regard to the study samples, the strength of this study is that it is multicenter; the study samples were randomly selected and separately taken from each of the three counties. The total population of the study samples included all patients (approximately 18,000 patients) in PHC with COPD or CHF in three counties. In spite of a low response rate, the sample size is not small as compared to other studies. . $^{911,26}$

Furthermore, the study has sufficient statistical power (90\% and $P$-value of 0.05 ); for example, a $9 \%$ difference of the prevalence of shortness of breath between the groups, required 120 individuals in each group.

\section{Conclusion and implications for practice}

The patient groups showed more similarities than differences in terms of symptoms and their impact on function and health - although there were differences in several background characteristics between patients with COPD and patients with CHF. Patients frequently have multiple symptoms, not only disease-specific, that need to be identified and managed both in groups and individually in PHC. It may be difficult to have separate interventions for all chronic diagnoses in PHC. Joint interventions based on symptoms and functioning for patients with these chronic diseases in PHC may offer the best hope for improving symptoms and their impact on function and health.

Future research in PHC should focus more on a holistic approach. This means taking the whole patient into account, including comorbidity that is based on the physician's diagnosis, and the effects of symptom management programs when combining, for example, patients with COPD and CHF. This study reports the prevalence of symptoms, but more research is needed for the multidimensional symptom approach.

\section{Acknowledgments}

This study was funded by: the Department of Research and Public Health in the County Council of Värmland; the Uppsala-Örebro Regional Research Council; and the Swedish Heart and Lung Association.

\section{Disclosure}

The authors report no conflicts of interest in this work.

\section{References}

1. Vestbo J, Hurd SS, Agustí AG, et al. Global strategy for the diagnosis, management, and prevention of chronic obstructive pulmonary disease: GOLD executive summary. Am J Respir Crit Care Med. 2013;187(4):347-365.

2. Bleumink GS, Knetsch AM, Sturkenboom MC, et al. Quantifying the heart failure epidemic: prevalence, incidence rate, lifetime risk and prognosis of heart failure The Rotterdam Study. Eur Heart J. 2004;25(18):1614-1619.

3. Mascarenhas J, Lourenço P, Lopes R, Azevedo A, Bettencourt P. Chronic obstructive pulmonary disease in heart failure. Prevalence, therapeutic and prognostic implications. Am Heart J. 2008;155(3):521-525.

4. Rutten FH, Cramer MJ, Grobbee DE, et al. Unrecognized heart failure in elderly patients with stable chronic obstructive pulmonary disease. Eur Heart J. 2005;26(18):1887-1894.

5. Hawkins NM, Jhund PS, Simpson CR, et al. Primary care burden and treatment of patients with heart failure and chronic obstructive pulmonary disease in Scotland. Eur J Heart Fail. 2010;12(1):17-24.

6. Rothman AA, Wagner EH. Chronic illness management: what is the role of primary care?. Ann Intern Med. 2003;138(3):256-261.

7. Ferrans CE, Zerwic JJ, Wilbur JE, Larson JL. Conceptual model of health-related quality of life. J Nurs Scholarsh. 2005;37(4):336-342.

8. Walke LM, Byers AL, Tinetti ME, Dubin JA, McCorkle R, Fried TR. Range and severity of symptoms over time among older adults with chronic obstructive pulmonary disease and heart failure. Arch Intern Med. 2007;167(22):2503-2508.

9. Blinderman CD, Homel P, Billings JA, Tennstedt S, Portenoy RK. Symptom distress and quality of life in patients with advanced chronic obstructive pulmonary disease. J Pain Symptom Manage. 2009;38(1): 115-123.

10. Bekelman DB, Rumsfeld JS, Havranek EP, et al. Symptom burden, depression, and spiritual well-being: a comparison of heart failure and advanced cancer patients. J Gen Intern Med. 2009;24(5):592-598.

11. Blinderman CD, Homel P, Billings JA, Portenoy RK, Tennstedt SL. Symptom distress and quality of life in patients with advanced congestive heart failure. J Pain Symptom Manage. 2008;35(6):594-603.

12. Cleeland CS. Symptom burden: multiple symptoms and their impact as patient-reported outcomes. J Natl Cancer Inst Monogr. 2007;37: $16-21$.

13. Paladini L, Hodder R, Cecchini I, Bellia V, Incalzi RA. The MRC dyspnoea scale by telephone interview to monitor health status in elderly COPD patients. Respir Med. 2010;104(7):1027-1034.

14. Walke LM, Gallo WT, Tinetti ME, Fried TR. The burden of symptoms among community-dwelling older persons with advanced chronic disease. Arch Intern Med. 2004;164(21):2321-2324.

15. Jansson-Bjerklie S, Carrieri VK, Hudes M. The sensations of pulmonary dyspnea. Nurs Res. 1986;35(3):154-159.

16. Mota DD, Pimenta CA. Self-report instruments for fatigue assessment: a systematic review. Res Theory Nurs Pract. 2006;20(1):49-78.

17. Theander K, Jakobsson P, Torstensson O, Unosson M. Severity of fatigue is related to functional limitation and health in patients with chronic obstructive pulmonary disease. Int J Nurs Pract. 2008;14(6): 455-462.

18. Hägglund L, Boman K, Olofsson M, Brulin C. Fatigue and healthrelated quality of life in elderly patients with and without heart failure in primary healthcare. Eur J Cardiovasc Nurs. 2007;6(3):208-215.

19. Yohannes AM, Willgoss TG, Baldwin RC, Connolly MJ. Depression and anxiety in chronic heart failure and chronic obstructive pulmonary disease: prevalence, relevance, clinical implications and management principles. Int J Geriatr Psychiatry. 2010;25(12):1209-1221.

20. Stege G, Vos PJ, van den Elshout FJ, Richard Dekhuijzen PN, van de Ven MJ, Heijdra YF. Sleep, hypnotics and chronic obstructive pulmonary disease. Respir Med. 2008;102(6):801-814.

21. Reimer MA, Flemons WW. Quality of life in sleep disorders. Sleep Med Rev. 2003;7(4):335-349.

22. McNicholas WT. Impact of sleep in COPD. Chest. 2000;117(Suppl 2): 48S-53S. 
23. Broström A, Strömberg A, Dahlström U, Fridlund B. Sleep difficulties, daytime sleepiness, and health-related quality of life in patients with chronic heart failure. J Cardiovasc Nurs. 2004;19(4):234-242.

24. Janssen DJ, Spruit MA, Uszko-Lencer NH, Schols JM, Wouters EF. Symptoms, comorbidities, and health care in advanced chronic obstructive pulmonary disease or chronic heart failure. J Palliat Med. 2011; 14(6):735-743.

25. Rabe KF, Hurd S, Anzueto A, et al; Global Initiative for Chronic Obstructive Lung Disease. Global strategy for the diagnosis, management, and prevention of chronic obstructive pulmonary disease: GOLD executive summary. Am J Respir Crit Care Med. 2007;176(6): $532-555$.

26. Dickstein K, Cohen-Solal A, Filippatos G, et al; ESC Committee for Practice Guidelines (CPG). ESC Guidelines for the diagnosis and treatment of acute and chronic heart failure 2008: the Task Force for the Diagnosis and Treatment of Acute and Chronic Heart Failure 2008 of the European Society of Cardiology. Developed in collaboration with the Heart Failure Association of the ESC (HFA) and endorsed by the European Society of Intensive Care Medicine (ESICM). Eur Heart J. 2008;29(19):2388-2442.

27. Portenoy RK, Thaler HT, Kornblith AB, et al. The Memorial Symptom Assessment Scale: an instrument for the evaluation of symptom prevalence, characteristics and distress. Eur J Cancer. 1994;30A(9): 1326-1336.

28. Fisk JD, Ritvo PG, Ross L, Haase DA, Marrie TJ, Schlech WF. Measuring the functional impact of fatigue: initial validation of the fatigue impact scale. Clin Infect Dis. 1994;18 Suppl 1:S79-S83.

29. Zigmond AS, Snaith RP. The hospital anxiety and depression scale. Acta Psychiatr Scand. 1983;67(6):361-370.

30. Bratås O, Grønning K, Forbord T. Psychometric properties of The Hospital Anxiety and Depression Scale and The General Health Questionnaire-20 in COPD inpatients. Scand J Caring Sci. 2014;28(2):413-420.

31. Bjelland I, Dahl AA, Haug TT, Neckelmann D. The validity of the Hospital Anxiety and Depression Scale. An updated literature review. J Psychosom Res. 2002;52(2):69-77.

32. Mahler DA, Wells CK. Evaluation of clinical methods for rating dyspnea. Chest. 1988;93(3):580-586.

33. Kinsman RA, Fernandez E, Schocket M, Dirks JF, Covino NA. Multidimensional analysis of the symptoms of chronic bronchitis and emphysema. J Behav Med. 1983;6(4):339-357.

34. Bastien $\mathrm{CH}$, Vallières A, Morin CM. Validation of the Insomnia Severity Index as an outcome measure for insomnia research. Sleep Med. 2001;2(4):297-307.

35. World Health Organization. ICF Checklist, Appendix 1, Brief Health Information. Geneva: World Health Organization; 2003. Available from: http://www.who.int/classifications/icf/training/icfchecklist.pdf. Accessed October 10, 2012.
36. Polit DF, Beck CT. Nursing Research: Generating and Assessing Evidence for Nursing Practice. 8th ed. Philadelphia: Lippincott Williams \& Wilkins; 2008.

37. Lenz ER, Pugh LC, Milligan RA, Gift A, Suppe F. The middle-range theory of unpleasant symptoms: an update. ANS Adv Nurs Sci. 1997; 19(3):14-27.

38. Miravitlles M, Ferrer J, Baró E, Lleonart M, Galera J. Differences between physician and patient in the perception of symptoms and their severity in COPD. Respir Med. 2013;107(12):1977-1985.

39. Furness S, Worthington HV, Bryan G, Birchenough S, McMillan R. Interventions for the management of dry mouth: topical therapies [review]. Cochrane Database Syst Rev. 2011;12:CD008934.

40. Yohannes AM, Lavoie KL. Overseeing anxiety and depression in patients with physical illness. Chest. 2013;144(3):726-728.

41. Zakrisson AB, Engfeldt P, Hägglund D, et al. Nurse-led multidisciplinary programme for patients with COPD in primary health care: a controlled trial. Prim Care Respir J. 2011;20(4):427-433.

42. Sava F, Laviolette L, Bernard S, Breton MJ, Bourbeau J, Maltais F. The impact of obesity on walking and cycling performance and response to pulmonary rehabilitation in COPD. BMC Pulm Med. 2010;10:55.

43. Lacasse Y, Goldstein R, Lasserson TJ, Martin S. Pulmonary rehabilitation for chronic obstructive pulmonary disease [review]. Cochrane Database of Syst Rev. 2006;4:CD003793.

44. Davies EJ, Moxham T, Rees K, et al. Exercise based rehabilitation for heart failure [review]. Cochrane Database Syst Rev. 2010;4: CD003331.

45. Barnes N, Calverley PM, Kaplan A, Rabe KF. Chronic obstructive pulmonary disease and exacerbations: clinician insights from the global Hidden Depths of COPD survey. Curr Med Res Opin. 2014;30(4): 667-694.

46. Evans RA, Singh SJ, Collier R, Loke I, Steiner MC, Morgan MD. Generic, symptom based, exercise rehabilitation; integrating patients with COPD and heart failure. Respir Med. 2010;104(10):1473-1481.

47. Hjerpe P, Merlo J, Ohlsson H, Bengtsson Boström K, Lindblad U. Validity of registration of ICD codes and prescriptions in a research database in Swedish primary care: a cross-sectional study in Skaraborg primary care database. BMC Med Inform Decis Mak. 2010;10:23.

48. Divo M, Cote C, de Torres JP, et al; BODE Collaborative Group. Comorbidities and risk of mortality in patients with chronic obstructive pulmonary disease. Am J Respir Crit Care Med. 2012;186(2):155-161.

49. Ahluwalia SC, Gross CP, Chaudhry SI, et al. Impact of comorbidity on mortality among older persons with advanced heart failure. $J$ Gen Intern Med. 2012;27(5):513-519.

50. Barnes S, Gott M, Payne S, et al. Recruiting older people into a large, community-based study of heart failure. Chronic Illn. 2005;1(4): 321-329.
International Journal of COPD

\section{Publish your work in this journal}

The International Journal of COPD is an international, peer-reviewed journal of therapeutics and pharmacology focusing on concise rapid reporting of clinical studies and reviews in COPD. Special focus is given to the pathophysiological processes underlying the disease, intervention programs, patient focused education, and self management protocols.
Dovepress

This journal is indexed on PubMed Central, MedLine and CAS. The manuscript management system is completely online and includes a very quick and fair peer-review system, which is all easy to use. Visit http://www.dovepress.com/testimonials.php to read real quotes from published authors. 